\title{
Imported fire ants carry high price
}

Establishment of red imported fire ants in California could cost the state's urban residents $\$ 257,771,386$ annually, according to a conservative estimate by Jay Hamilton, a UC Riverside graduate student, given at a recent UC Agricultural Issues Center conference on exotic pests.

A native of South America and established in many parts of the southern United States, the aggressive pest was detected in the San Joaquin Valley in 1997 and is now found in Fresno, Kern, Orange, Los Angeles, Riverside and San Diego counties. Hamilton calculated the ant's nearly $\$ 258$ million price tag by studying a survey on its costs conducted by Arkansas officials. The estimate includes only costs of pesticides, replacement of damaged electrical equipment and medical treatment, not significant potential agricultural and ecological expenses.

Hamilton said his figures, and the Red imported fire ant queen being tended by workers.

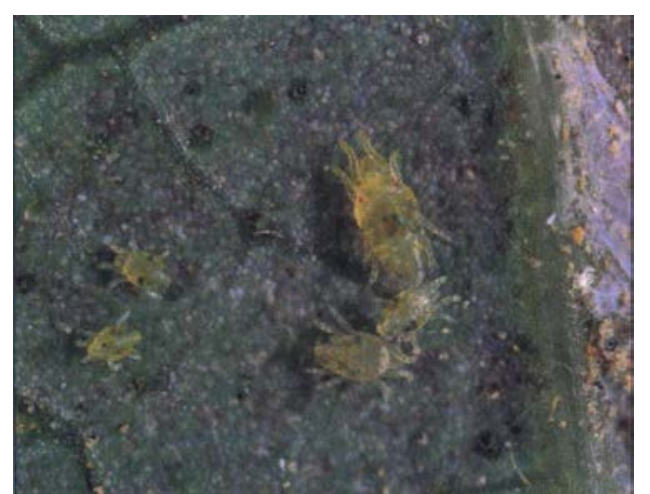

Persea mites nuisance caused by the pest, underscore the urgency to eradicate red imported fire ant rapidly and completely from the state.

\section{Persea mite, thrips threaten avocados}

Two tiny pests that recently entered the United States, the persea mite and avocado thrips, pose a formidable threat to California's estimated 6,000 avocado growers, say UC researchers. The mite feeds on leaves, causing them to fall from trees, while feeding thrips damage young fruit, turning them brown.

Mark Hoddle, UC Riverside biological control specialist, and Karen Jetter, UC Davis postdoctoral researcher, have developed an economic model to determine the effects to growers and consumers of the rising production costs, decreasing quality and increased market prices caused by the persea mite and avocado thrips. Initial results show an annual short-run loss to growers of between $\$ 7.6$ million and $\$ 13.4$ million. Annual short-run losses to consumers from higher prices are estimated between $\$ 6.8$ million and $\$ 10.2$ million.

Because seasonal avocado imports from countries like Chile and Mexico are rising, the increasing production costs for California growers may not translate into higher prices in the marketplace. Rather, increased imports could replace local production. This could result in a smaller impact on consumers, but an even greater impact on California avocado growers, who produce $90 \%$ of the nation's crop. Growers in San Diego County, where nearly half of the state's crop originates, are at greatest risk.

\section{CALFED publishes preferred options for Bay-Delta}

Since its inception in June 1995, the CALFED Bay-Delta program - a federal-state partnership - has attempted to develop solutions for restoring ecological health to the San Francisco BaySan Joaquin Delta, while satisfying the competing interests of farmers, environmentalists, water suppliers and businesses. The 738,000acre Bay-Delta system irrigates 200 types of crops, producing $45 \%$ of the nation's fruits and vegetables, according to CALFED.

On June 25, 1999, CALFED released its draft environmental impact report (EIR), which identifies "preferred" options for the Bay-Delta. The plan, set forth in a multivolume report, describes a series of long-term programs including levee system integrity, water quality, ecosystem restoration, water-use efficiency, water transfers, watershed management, and storage and delta conveyance.

The 30-year restoration program is expected to cost $\$ 10$ billion. About $\$ 301$ million will be spent on early ecosystem restoration projects through 1999, such as habitat restoration, fish ladders, land acquisition, and research and monitoring.

Beginning Aug. 18, CALFED will host 15 public hearings around the state on the draft EIR and preferred options. A 90-day public comment period concludes Sept. 23. The plan is scheduled to be finalized by June 2000 .

For more information, go to the CALFED website at http:/ / calfed.ca.gov or call 1-800700-5752. Copies of CALFED documents are available in many local libraries. 